\title{
Developing a rational approach to surgical site infection prevention in a tertiary care hospital in Cairo
}

\author{
Nagwa Khamis, $M D$ \\ Department of clinical pathology and infection control ASUSH
}

\begin{abstract}
Surgical site infections (SSI) account for a large proportion of hospital acquired infections. They are associated with high morbidity and mortality that poses a large burden upon inpatient's health care budget. Prevention is desirable and it consists of a combination of preoperative patient and operation room environment preparation, appropriate surgical techniques, preoperative antibioprophylaxis and postoperative wound care.

Surveillance of SSI was conducted, in a tertiary care hospital in Cairo, as a part of the infection control program. This study represents SSI over 2006 in general and specialized surgeries. Cases were identified according to data analyzed from the infection notification forms and the microbiology reports of positive cultures. The isolated microorganisms as well as their sensitivity/resistance pattern were illustrated. Results showed infection rates in Clean surgeries: 1.05\%, Clean-contaminated: $0.8 \%$, Contaminated: $4.7 \%$ and Dirty: $8 \%$, in general type of surgery-wound class. Other measures for SSI prevention were highlighted as patient preoperative preparation, biological assessment of operation room environment and antibioprophylaxis which is implemented and properly followed since July 2005 to date. Cycling of the antibiotic policy was done three times and updated according to new requirements. Measuring SSI rates is a major challenge in hospitals where limited experience with measurement of outcomes exists. However it is one of the quality performance indicators in health care settings.
\end{abstract}

\section{Introduction:}

Surgical site infections (SSI) are one of the most important health care associated infections (HAI). ${ }^{1}$

Before the mid-9th century, surgical patients commonly developed postoperative "irritative fever" followed by purulent drainage from their incisions, overwhelming sepsis, and often death. Till late 1860s, came Joseph Lister who introduced the principles of antisepsis and changed radically the outcome of surgery from an activity associated with infection and death to a discipline that could eliminate suffering and prolong life. ${ }^{2}$

Based on the National Nosocomial Infections Surveillance (NNIS) system reports, SSI are the third most frequently reported nosocomial infection, accounting for $14 \%$ to $16 \%$ of all nosocomial infections among hospitalized patients. ${ }^{3}$ In many countries SSI account for up to $25 \%$ of HAIs. ${ }^{1}$

By definition, any infection occurring within 30 days of an operation or within one year of an implant procedure is classified as SSI. ${ }^{4}$ The identification involves interpretation of clinical and laboratory findings and it is crucial that a surveillance program uses definitions that are consistent and standardized; otherwise, inaccurate SSI rates will be computed and reported. ${ }^{2}$

Surveillance of SSI with appropriate feedback to surgeons has been shown to reduce SSI risk. A surveillance system should include standard definitions and risk stratification of patients. The main predictor of SSI was regarded as the intrinsic degree of wound contamination. Wounds were classified as clean, clean-contaminated, contaminated and dirty. 5,6

In the context of SSI pathophysiology, the term risk factor refers to variables that have significant association with the development of infection. ${ }^{7}$ In the broad sense, they include factors in relation to patients ${ }^{8}$ or operation features as wound class, operation room environment, asepsis and the surgical 
technique. ${ }^{8}$

Another additional factor is the antibioprophylaxis which refers to agent initiated just before operation. It can effectively prevent the infectious complications and shortens the postoperative hospital stay. ${ }^{10}$

However despite the advances in antibiotic prophylaxis, SSI remains a major source of morbidity and its prevention is a challenging problem, especially in high risk patients. ${ }^{1}$

\section{Method:}

Surveillance of SSI was conducted in a 300 beds tertiary care hospital( El-Kahraba hospital) in Cairo, as a part of the infection control program. The study represents SSI over 2005 through 2006 in all types of surgeries, in reference to wound class.

Cases were identified according to data analyzed from the infection notification forms and the microbiology reports of positive cultures. The isolated microorganisms as well as their sensitivity/resistance pattern were illustrated.

Setting of infection control measures in relation to preoperative patient preparation, biological assessment of the operating room environment and quality control of the sterilization procedures, were done.

An antibiotic prophylaxis policy was formulated and properly followed since 2005 to date. Cycling was done three times with up date of the currently used antibiotics.

\section{SSI prevention protocol:}

* Hospital environment.

* Operation.

* Patient.

\section{**OR environment:}

1- Disinfection policy (daily and weekly cleaning) of operating rooms.

2- Quality control of sterilization process: * Biological spore test.

* Integrator indicator.

3- Biological assessment of the environment.

\section{**Operation:}

1- Duration of hand scrub (5 min Betadine, 2 min Alcohol).

2- Duration of operation.
3- Sterilization of instrument

4- Foreign material in the site of surgery (sterile).

5- Surgical technique.

6- Fluids in use (sterile).

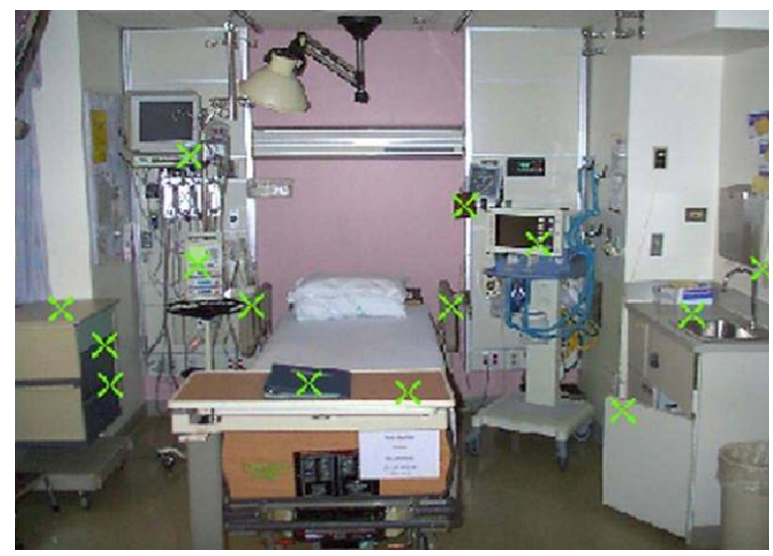

Figure (1): Potential sources of contamination in an operating room

\section{**Preoperative patient preparation}

1- Patient shower.

2- Preoperative skin preparation done by trimming of hairs and antisepsis of site of surgery using betadine (twice).

3- Antibiotic prophylaxis policy.

**Antibiotic prophylaxis policies in surgeries

Different policies were developed since July 2005 and cycling was three times. Last version was emerged on March 2007.

\section{Results:}

Follow up of the implementation of infection control measures revealed the following: 1- Proper preoperative skin preparation, which was done in the patient's wards.

2- Good compliance of the surgeons for the implementation of the antibioprophylaxis in different types of surgeries Table(1).

3- The SSI rates were all within the accepted range except for the orthopedic "dirty" type of operation was $50 \%$ in 2005; but the same type was much improved on 2006 Tables(2\&3).

4- The isolated microorganisms didn't show high resistance pattern, in addition not a single case of MRSA was isolated from culture of infected cases. 
Table (1): Evaluation of the first cycle of antibioprophylaxis.

\begin{tabular}{|l|c|c|c|}
\hline Department & $\begin{array}{c}\text { Total no. of } \\
\text { surgeries }\end{array}$ & $\begin{array}{c}\text { Number of } \\
\text { exceptions }\end{array}$ & Compliance rate \\
\hline $\begin{array}{l}\text { General } \\
\text { surgeries }\end{array}$ & 255 & 10 & $96 \%$ \\
\hline Urosurgeries & 93 & 5 & $95 \%$ \\
\hline
\end{tabular}

Table (2): Surgical site infection rates over 2005.

\begin{tabular}{|l|c|c|c|c|}
\hline & $\begin{array}{c}\text { General } \\
\text { surgery }\end{array}$ & $\begin{array}{c}\text { Orthopedic } \\
\text { surgery }\end{array}$ & $\begin{array}{c}\text { Uro - } \\
\text { surgery }\end{array}$ & $\begin{array}{c}\text { Neuro - } \\
\text { surgery }\end{array}$ \\
\hline $\begin{array}{l}\text { Clean } \\
\mathbf{1 . 5 \% - 3 \%}\end{array}$ & $0.9 \%$ & $1.08 \%$ & $0 \%$ & $1.25 \%$ \\
\hline $\begin{array}{l}\text { Clean-contam. } \\
\mathbf{3 \% - 4 \%}\end{array}$ & $3.8 \%$ & $3.8 \%$ & $0 \%$ & $0 \%$ \\
\hline $\begin{array}{l}\text { Contam. } \\
\mathbf{8 . 5 \%}\end{array}$ & $1.9 \%$ & $0 \%$ & $4.2 \%$ & $0 \%$ \\
\hline $\begin{array}{l}\text { Dirty } \\
\mathbf{2 8 \% - 4 0 \%}\end{array}$ & $9.5 \%$ & $50 \%$ & $0 \%$ & $0 \%$ \\
\hline
\end{tabular}

Table(3): Surgical site infection rates over 2006.

\begin{tabular}{|l|c|c|c|c|}
\hline & $\begin{array}{c}\text { General } \\
\text { surgery }\end{array}$ & $\begin{array}{c}\text { Orthopedic } \\
\text { surgery }\end{array}$ & $\begin{array}{c}\text { Uro - } \\
\text { surgery }\end{array}$ & $\begin{array}{c}\text { Neuro - } \\
\text { surgery }\end{array}$ \\
\hline $\begin{array}{l}\text { Clean } \\
\mathbf{1 . 5 \% - 3 \%}\end{array}$ & $\begin{array}{c}1.05 \% \\
(6 / 567)\end{array}$ & $\begin{array}{c}1.2 \% \\
(5 / 372)\end{array}$ & $0 \%$ & $\begin{array}{c}0.3 \% \\
(1 / 287)\end{array}$ \\
\hline $\begin{array}{l}\text { Clean-contam. } \\
\mathbf{3 \% - 4 \%}\end{array}$ & $\begin{array}{c}0.8 \% \\
(1 / 117)\end{array}$ & $0 \%$ & $0 \%$ & $0 \%$ \\
\hline $\begin{array}{l}\text { Contam. } \\
\mathbf{8 . 5 \%}\end{array}$ & $\begin{array}{c}4.7 \% \\
(12 / 254)\end{array}$ & $0 \%$ & $0 \%$ & $0 \%$ \\
\hline $\begin{array}{l}\text { Dirty } \\
\mathbf{2 8 \% - 4 0 \%}\end{array}$ & $\begin{array}{l}8 \% \\
(6 / 75)\end{array}$ & $\begin{array}{c}(2 / 12) \\
(6.6 \%\end{array}$ & $0 \%$ & $10 \%$ \\
$(1 / 10)$
\end{tabular}


Table (4): Antibiotic sensitivity/resistance pattern of SSI nosocomial isolated microorganisms.

\begin{tabular}{|l|c|c|}
\hline $\begin{array}{c}\text { Isolated } \\
\text { Microorganisms }\end{array}$ & $\begin{array}{c}\text { Sensitivity to } \\
\text { antibiotics }\end{array}$ & Resistance to antibiotics \\
\hline Klebsiella spp & $\begin{array}{c}\text { Amikin, } \\
\text { Teinam, } \\
\text { Meronem }\end{array}$ & Augmentin, Ciprinol, Sutrim \\
\hline $\begin{array}{l}\text { Other gram-ve } \\
\text { bacilli }\end{array}$ & $\begin{array}{c}\text { Amikin, Teinam, } \\
\text { Meronem, Ciprinol, } \\
\text { Sulperazone, } \\
\text { Claforan }\end{array}$ & $\begin{array}{c}\text { Augmentin, Fortum, } \\
\text { Levofloxacin, Sutrim }\end{array}$ \\
\hline Streptococci & $\begin{array}{c}\text { Amikin, Teinam, } \\
\text { Meronem, Ciprinol, } \\
\text { Cefobid }\end{array}$ & $\begin{array}{c}\text { Augmentin, Fortum, } \\
\text { Claforan, Sutrim }\end{array}$ \\
\hline
\end{tabular}

Study of the antibiotic consumption done by the pharmacy department showed much decrease in the 3 rd and 4th generation cephalosporin by about $50 \%$.

\section{Discussion:}

SSI undoubtedly reflects on the skill of an individual surgeon. A careful surgeon who handles the tissues gently, securing good hemostasis and who works moderately quickly with excellent aseptic techniques may have lower sepsis rates. ${ }^{12}$ However, the type of surgical wound is the most important single factor associated with the development of infections, since it defines the degree of intraoperative microbial contamination. ${ }^{5}$

Surgeons use antimicrobial prophylaxis by anticipating preoperatively the surgical wound class for a given operation. ${ }^{2}$

An effective prophylactic regimen should be directed against the most likely infecting organisms but need not to eradicate every potential pathogen; rather the goal is to decrease their numbers below critical levels necessary to cause infection. For most procedures first generation cephalosporin (cefazolin), which has a moderately long serum half-life, has been effective. The benefit of antimicrobial prophylaxis must be weighed against the risks of toxic and allergic reactions, emergence of resistant bacteria and super infection. ${ }^{13}$ Consequently, on implementing the antibioprophylaxis in the current study, shift to 1 rst generation cephalosporin in clean surgeries was done then followed by "No antibioprophylaxis" in the last cycling for the same type of surgeries. This policy helped much in preventing emergence of multidrug resistant bacteria causing SSI, as evidenced by the absence of even a single case of MRSA infection. On the other hand, appropriate implementation of infection control measures as disinfection of operating rooms, biological assessment of the environment and efficient preoperative preparation of the patient, had improved the outcome of surgical procedures. This agreed with Vegas et al. who concluded that advances in infection control practices include improved operating room ventilation, sterilization methods, barriers, surgical techniques and availability of antibioprophylaxis. ${ }^{14}$

In conclusion, optimum application of SSI prevention measures requires that a variety of patient and operation characteristics be carefully considered.

\section{References:}

1- Brenner P and Nercelles P: Prevention of surgical site infection. In: Basic concepts of infection control. UK (N Ireland): International Federation of Infection Control; Chapter 11; 2007.

2- Mangram AJ, Horan TC, Pearson ML, et al: Guidelines for prevention of surgical site infection. Am J Inf Cont 1999; 27: 97 134.

3- Emori TG, Gaynes RP: An overview of nosocomial infections including the role of the microbiology laboratory. Clin Microbio Rev 1993; 6(4): 428-442. 
4- Horan TC, Gaynes RP, Martone WJ, et al: CDC definitions of nosocomial surgical site infections: A modification of CDC definitions of surgical wound infections. Infect Cont Hosp Epidemiol 1992; 13(10): 606-608.

5- Garnier JS: CDC guidelines for prevention of surgical wound infections. Revised Infect Control 1986; 7(3): 193-200.

6- Simmons BP: Guidelines for prevention of surgical wound infection. Infection Control 1982; 3: 185-196.

7- Lee JT: Surgical wound infections: Surveillance for quality improvement. In: Surgical Infections. Fry DE, (Editor); Boston: Little, Brown and Co (Publishers); 1995; p. 145-159.

8- SHEA, APIC, CDC, SIS: Consensus paper on the surveillance of surgical wound infections. Infect control Hosp Epidemiol 1992; 13(10): 599-605.

9- Pittet D, Ducel G: Infectious risk factors related to operating rooms. Infect Control Hosp Epidemiol 1994; 15: 456-462.
10-Doganov N, Shtereva K, Dimitrov K: A comparative study of the efficacy of antibiotic prophylaxis with cephalosporin in operative gynecology. Akush Ginekol (Sofia) 1998; 37: 29-33.

11-Larson EI, Pearson MI, Lee JT: Guidelines for prevention of surgical site infection. Infect Cont Hosp Epidemiol 1999; 20: 248-272.

12-Shanson DC: Hospital infection. In: Microbiology in Clinical Practice. Butterworth and Heinemann; 3rd edn.1999; Chapter 26: 429-458.

13-Kaiser AB: Principles and Practice of Infectious Diseases. GL Mandell (Editor); New York: Churchill Livingstone (Publisher); 3rd edn.1990; p. 2245. 14-Vegas AA, Jodra VM, Garcia MI: Nosocomial infection in surgery wards: a controlled study of increased duration of hospital stay and direct cost of hospitalization. Eur J Epidemiol 1993; 9(5): 504-510. 